\title{
Thermorheological and Textural Behaviour of Gluten-Free Gels Obtained from Chestnut and Rice Flours
}

\section{María D. Torres, Patricia Fradinho, Anabela Raymundo \& Isabel Sousa}

Food and Bioprocess Technology An International Journal

ISSN 1935-5130

Food Bioprocess Technol

DOI 10.1007/s11947-013-1132-6

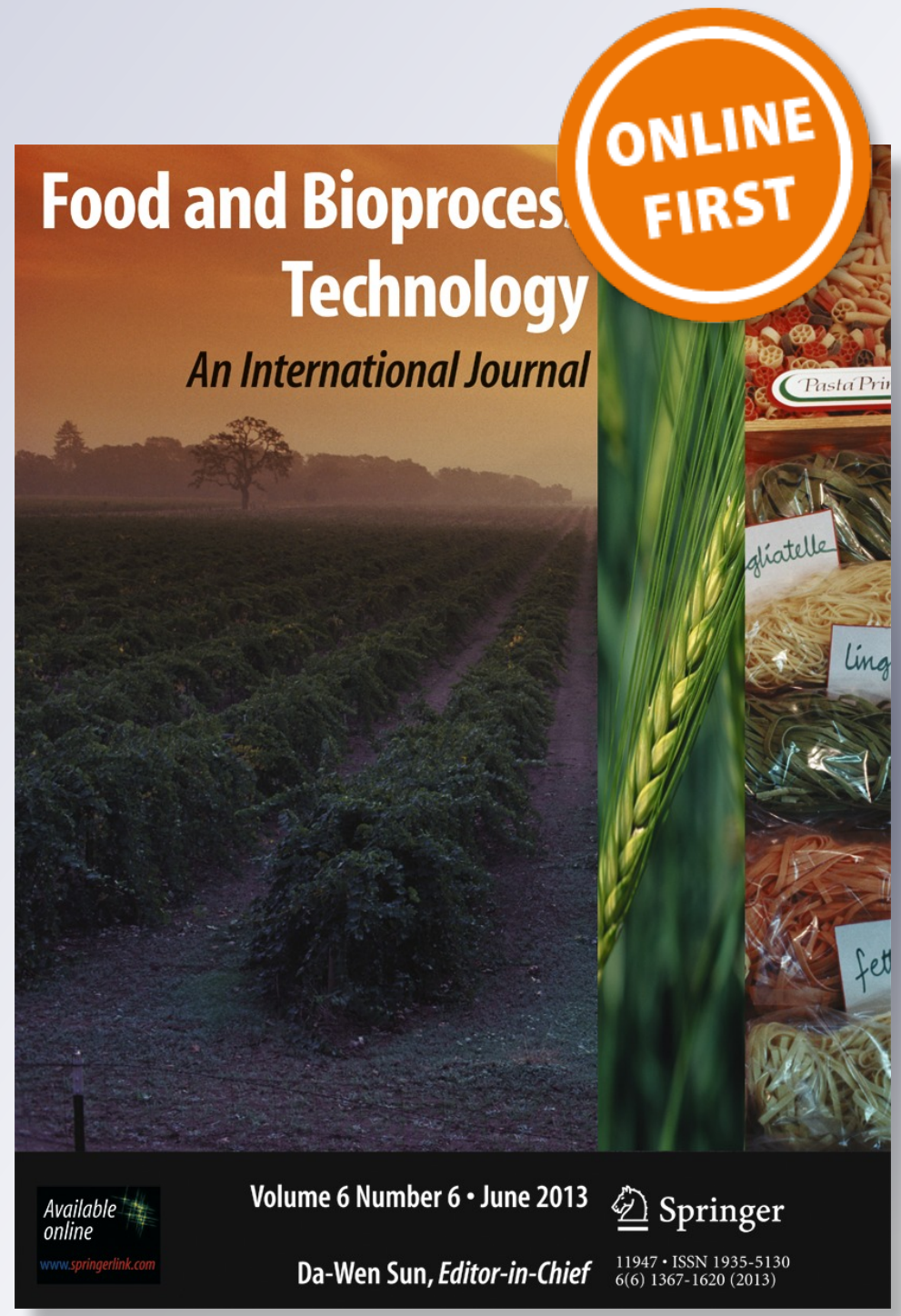

脰 Springer 
Your article is protected by copyright and all rights are held exclusively by Springer Science +Business Media New York. This e-offprint is for personal use only and shall not be selfarchived in electronic repositories. If you wish to self-archive your article, please use the accepted manuscript version for posting on your own website. You may further deposit the accepted manuscript version in any repository, provided it is only made publicly available 12 months after official publication or later and provided acknowledgement is given to the original source of publication and a link is inserted to the published article on Springer's website. The link must be accompanied by the following text: "The final publication is available at link.springer.com". 


\title{
Thermorheological and Textural Behaviour of Gluten-Free Gels Obtained from Chestnut and Rice Flours
}

\author{
María D. Torres • Patricia Fradinho • \\ Anabela Raymundo • Isabel Sousa
}

Received: 29 January 2013 / Accepted: 15 May 2013

(C) Springer Science+Business Media New York 2013

\begin{abstract}
Nowadays, as celiac disease is becoming more common the consumers' demand for gluten-free products with high nutritional and taste quality is increasing. This work deals with the study of the impact of four novelty gluten-free sources: chestnut flour (Cf), whole rice flour $(\mathrm{Rw})$, Carolino rice flour (Rc) and Agulha rice flour (Ra). Textural, thermorheological and stability performance of gluten-free gels using different experimental techniques were evaluated. Mixed gels were also produced for comparison. Texture parameters were determined from the texture profile analysis using a texturometer. Thermorheological oscillatory measurements were conducted in a stresscontrolled rheometer in order to clarify the kinetics of gel formation and to characterise the structure of the matured gels. The stability of the gels was evaluated using transmittance profiling of the gels under gravitational fields $\left(\right.$ LUMiSizer $\left.^{\circledR}\right)$. Texture studies suggested that gels from
\end{abstract}

\section{D. Torres $(\square)$}

Departamento de Enxeñaría Química, Escola Técnica

Superior de Enxeñaría, Universidade de

Santiago de Compostela, Campus Vida,

E-15782 Santiago de Compostela, Spain

e-mail: mariadolores.torres.perez@usc.es

\section{P. Fradinho}

Instituto Piaget. Núcleo de Investigação em Engenharia Alimentar e Biotecnologia-ISEIT Almada, Quinta da Arreinela de Cima, 2800-305 Almada, Portugal

\section{A. Raymundo \\ Instituto Piaget. Núcleo de Investigação em Engenharia Alimentar e Biotecnologia-ISEIT Almada, Quinta da Arreinela de Cima, 2800-305 Almada, Portugal}

A. Raymundo $(\bowtie) \cdot$ I. Sousa $(\bowtie)$

CEER-Biosystems Engineering, Instituto Superior de Agronomia/

Technical University of Lisbon, Tapada da Ajuda,

1349-017 Lisboa, Portugal

e-mail: araymundo@almada.ipiaget.org

e-mail: isabelsousa@isa.utl.pt mixtures of chestnut flour at $30 \%$ and rice flour at $20 \%$ showed the right texture to develop gel-based new desserts. Rheological results showed that the thermal profiles on heating of $\mathrm{Cf}$ gels were similar to those obtained for $\mathrm{Rw}$ and $\mathrm{Ra}$, whereas Rc gels exhibited a particular pattern. Once the final gelatinisation temperature was achieved, no significant differences on the viscoelastic properties were noticed for all the tested gels. Stability tests showed that gels with Rc should present an industrial advantage over the other assayed formulations, since the stability of these gels is of the order of four times larger.

Keywords Chestnut flour · Rice flours · Gluten-free · Gels · Rheology · Texture

\section{Introduction}

The demand for high-quality gluten-free foodstuffs has considerably increased in recent years due to an increase in diagnosed celiac patients. The employed formulations to develop these products involve a large number of alternative flour types to wheat flour such as corn, cassava, rice, soybean, chickpea or amaranth flours as well as its blends (Brites et al. 2008; Marco and Rosell 2008; Houben et al. 2010; Moreira et al. 2012a). Nevertheless, many gluten-free products available on the market are based on formulations with low technological and nutritional quality, particularly compared with their wheat counterparts (Mariotti et al. 2009). One possibility with a great potential to improve the quality of these products could be the chestnut flour (Cf), due to its organoleptic and nutritional characteristics (Borges et al. 2007; Moreira et al. 2012b). Namely, Cf contains proteins with a high content of essential amino acids (4.0-7.0 \%), low fats (2.0-4.0 \%), high vitamin $\mathrm{E}$, vitamin $\mathrm{B}$ group, potassium, phosphorous and magnesium content, appreciable levels of dietary fibre (5$15 \%)$, relatively high amount of sugar, mainly sucrose (20- 
$32 \%$ ) and starch (50-60\%) (Sacchetti et al. 2004; Vasconcelos et al. 2010). Since most gluten-free products do not contain sufficient amounts of these compounds (Lazaridou et al. 2007; Moroni et al. 2009), it may be advantageous to use Cf. Although $\mathrm{Cf}$ shows beneficial nutritional characteristics, there are some technological constrains, and this flour has been used as a minor ingredient in commercial products. It is known that dough with this flour originate baked products with low volume and unacceptable brownish colour (Demirkesen et al. 2010) as well as inadequate viscoelastic properties mainly by high viscosity values and low elasticity (Moreira et al. 2012b). Recently, some new formula products (snacks, flakes, spaghetti) from $\mathrm{Cf}$ are available in countries such as Italy and France making the market possibilities very attractive. The latter study (Moreira et al. 2012b) indicated the improvement of Cf doughs in the presence of rice flour (Rf). In the same way, $\mathrm{Cf}$ was found to be suitable for the extrusion-cooking process adopted if properly mixed with $\mathrm{Rf}(30 \% \mathrm{Cf}$ percentage) to make a snack-like product (Sacchetti et al. 2004). Hence, the blending of Cf with other flours, such as Rf seems an interesting approach (Demirkesen et al. 2010) to produce gluten-free products.

Rice flour is the most common cereal grain flour for the production of gluten-free products due to its bland taste, white colour, digestibility, lightness and hypoallergenic properties. In addition, other attributes such as the low content of protein, sodium and fat as well as the presence of easily digested carbohydrates make rice the flour preferred for patients suffering from food allergies (Gujral and Rosell 2004; Lawal et al. 2011). Like other cereals, the Rf characteristics are governed by inherent cultivar's variations, environmental variation, the grinding methods and their previous treatments (Rosell and Gómez 2006). Rice flours mainly differ in the pasting behaviour and viscoelastic properties. Since these factors influence the behaviour during processing, careful selection of the rice cultivars used in the grinding is recommended to obtain suitable flour. In general, the long-grain $(>6.6 \mathrm{~mm})$ varieties have higher gelatinisation temperatures and a larger tendency to retrograde than medium (between 5.5 and $6.6 \mathrm{~mm}$ ) or short-grain $(<5.5 \mathrm{~mm})$ varieties. A good approach to the production of gluten-free products could be the use of $\mathrm{Cf}$ blended with $\mathrm{Rf}$ flours or starches (Gallagher et al. 2004). This is also a strategy to add value to the chestnut and rice industry by-products. These industries are relevant in countries like Portugal and Spain. In particular, "Carolino rice" is a traditional Portuguese variety with peculiar gastronomic properties.

The structure of gel or paste depends not only on the starch concentration but also on the interactions between components and heating conditions such as time, temperature and rate of heating (Funami et al. 2008). It was demonstrated that starchy materials reinforce the structure of protein and kcarrageenan gels acting as filler (Nunes et al. 2004, 2006).
Analysis of pasting behaviour and viscoelastic properties is a useful method to determine the properties of these systems (Rosell and Gómez 2006; Sodhi et al. 2010). In the processing of wheat flour-based food products, direct relationships were identified between the rheological properties of gels, its structure and quality of the finished product (Manohar and Rao 2002).

The challenge is to understand how the gluten-free flours behave under food processing conditions since the final structure and texture properties of these systems are strongly dependent on processing temperature/time, cooling rates, flour composition and its content, and $\mathrm{pH}$ conditions. During gel formation, all these factors can affect the dynamic process of competition between phase separation and gel formation (Rosalina and Bhattacharya 2002). The influence of thermal treatment and composition on the mechanical properties of the gluten-free flour gels has been scarcely studied. Therefore, the main aim of this study is to evaluate the effect of thermal conditions on the gel-forming kinetics, final mechanical properties and stability of these systems. To achieve this, a systematic investigation of the rheological and textural behaviour of four gluten-free sources of flour: chestnut flour (Cf), whole Agulha rice flour (Rw), Carolino rice flour $(\mathrm{Rc})$ and Agulha rice flour $(\mathrm{Ra})$ has been performed. These gelling properties can be used to the development of alternative gluten-free desserts with commercial applications. The evolution of the structure of these systems was monitored by rheological testing at small amplitude oscillatory shear (SAOS). Texture properties of the final gels were also determined as well as their stability. Relevant physicochemical properties of flours were determined as a reference for the understanding of these systems.

\section{Materials and Methods}

\section{Raw Materials}

Two commercial gluten-free flours: chestnut flour (Cf) (Naiciña, Spain) and whole Agulha rice flour (Rw) (Próvida, Portugal) were used. Other two rice grain sources, Carolino rice and Agulha rice, were employed to obtain the corresponding flours, Rc and Ra, respectively, with comparative purposes. The latter two materials were kindly provided by the manufacturer (Novarroz, Portugal). Rc and Ra flours were obtained using a domestic electric mill with a constant speed.

\section{Particle Size Distribution}

Different standard sieves $(750,350$ and $75 \mu \mathrm{m})$ of $200 \mathrm{~mm}$ diameter were employed to determine the particle size distribution of all tested flours. The highest fraction of each type of 
flour $(>350 \mu \mathrm{m})$ was removed. The sieving procedure was carried out according to ASAE Standards (1995). The fractions retained in each of the different meshes were separated and weighed. The fractionation process was performed in triplicate for each sample. The calculated average particle size $\left(D_{\mathrm{w}}\right)$ and distributions were obtained taking into account the amounts of flour retained in each sieve.

\section{Chemical composition}

Initial moisture content of all systems was determined according to ICC-Standard Methods No. 110/1 (ICC 2008). Total fat amount of flours was determined following ISO 7302 (1982). Total, soluble and insoluble dietary fibre content of flours was evaluated by means of a standard enzymatic-gravimetric method according to AOAC official method No. 991.43 (AOAC 1996). The latter components have high importance in the gels behaviour when thermal effects are involved. All chemicals used for $\mathrm{pH}$ solutions and other reagents for different tests were of analytical grade. The assays were performed at least in triplicate.

\section{Swelling Power and Solubility}

Swelling power and solubility were determined following a modification of the method developed by Leach et al. (1959). The method involved a suspension of flour in a known volume of water, gently stirring to keep it in suspension while incubating it at desired temperature $(40,60,70$, 80 and $90^{\circ} \mathrm{C}$ ) for $30 \mathrm{~min}$, centrifuging it at 3,000 rpm for $15 \mathrm{~min}$, and obtaining the weight of the gel, which is expressed as sediment paste per gram (d.b.) of the flour. Solubility of the flour is obtained by drying the supernatant at $105 \pm 1{ }^{\circ} \mathrm{C}$ and is expressed as percentage soluble. This test has always been extensively used in the characterization of flours (Collado and Corke 2003).

\section{Gel Preparation}

Preliminary assays were performed in order to establish the best protocol for the gels preparation. Single suspensions of the individual flours (Cf, Rw, Rc and Ra) were prepared at different flour concentrations $(20,25,30,35$ and $40 \%, w / w)$ with demineralised water and subjected to several thermal treatments. Namely, the suspensions were heated up at 70 , 80 and $90^{\circ} \mathrm{C}$ and kept at these temperatures for 15,30 and $60 \mathrm{~min}$. The best conditions were selected after texture measurements and empirical visual characterisation.

Gels were prepared using $\mathrm{Cf}$ and each of the three rice flours (Rw, Rc and Ra) at several ratios (\%) (Cf/Rf, 0/100, $20 / 80,40 / 60,50 / 50,60 / 40,80 / 20$ and 100/0). The formulations contained demineralised water at levels that provide total flour content of 20 and $30 \%(w / w)$ and were dispersed by stirring at $800 \mathrm{rpm}$ for $10 \mathrm{~min}$ on a magnetic hotplate stirrer (Arex, Velp Scientifica, Italy) at room temperature. To prepare the gels, these suspensions were heated up to $90^{\circ} \mathrm{C}$ and kept at this temperature for $30 \mathrm{~min}$. Subsequently, samples were placed in a fridge in order to allow full maturation of the gels, which were kept at $5{ }^{\circ} \mathrm{C}$ for $24 \mathrm{~h}$ before performing texture and stability measurements. This time is enough to ensure the maturation of the gels structure. For rheological measurements, the flour suspensions dispersed at room temperature were immediately poured into the rheometer-measuring system after $10 \mathrm{~min}$ stirring to promote gelatinisation in situ, avoiding further perturbations of the gel matrix.

\section{Colour measurements}

The colour measurements of all gels were performed instrumentally using a Minolta CR-300 (Minolta Co., Osaka, Japan) tristimulus colorimeter with standard illuminant D65 and a visual angle of $2^{\circ}$. The colour parameters $\left(L^{*}, a^{*}\right.$ and $\left.b^{*}\right)$ were assessed by CIELAB, where $\mathrm{L}^{*}$ defines the lightness and $\mathrm{a}^{*}$ (degree of redness or greenness) and $\mathrm{b}^{*}$ (degree of yellowness or blueness) are the chromaticity responsible parameters. For the assessment of the colour, these parameters were combined to obtain the whiteness $\left(100-\left[\left(100-\mathrm{L}^{*}\right)^{2}+\right.\right.$

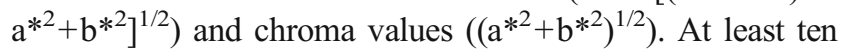
measures were carried out for each sample.

\section{Texture Measurements}

Firmness was determined from the texture profile analysis (TPA) using a TA-XT2i (Stable Micro Systems, UK) texturometer (load cell of $5 \mathrm{~kg}$ ) in a double-cycle penetration mode. Penetration assays were performed in the gels contained in a cylindrical flask $(2.5 \mathrm{~cm}$ diameter and $4.5 \mathrm{~cm}$ height) filled up to about $90 \%$, i.e., $4 \mathrm{~cm}$ height of gel, using a cylindrical stainless steel probe of $11 \mathrm{~mm}$ diameter $(5 \mathrm{~mm}$ of penetration and $2 \mathrm{~mm} / \mathrm{s}$ of crosshead speed). The tests were carried out $24 \mathrm{~h}$ after preparation of the samples in order to allow full maturation of the gels. Before performing any measurements, gels were allowed to equilibrate at $20^{\circ} \mathrm{C}$ for approximately $1 \mathrm{~h}$ in a temperature-controlled room. Each formulation was tested at least in triplicate. From the experimental force versus time data, the maximum force (correlated with firmness) was calculated. Firmness $(N)$ was considered as the maximum resistance to the penetration of the probe and was calculated as the height of the force peak during the first compression cycle (Bourne 2002).

Rheological Measurements

Rheological measurements were carried out on a RS-75 controlled stress rheometer (Haake, Germany) using serrated parallel plates (35 mm diameter and $0.500 \mathrm{~mm}$ gap) to 
prevent wall slip effect as recommended by several authors (Franco et al. 1998). Temperature was controlled by a DC5 circulating water bath (Haake, Germany) and measured with a thermocouple attached to the stationary element. Aqueous flour suspensions were loaded carefully between the plates to ensure minimal structural damage and held at rest for $10 \mathrm{~min}$ before testing to allow temperature equilibration $\left(20{ }^{\circ} \mathrm{C}\right)$. The exposed edges of the sample were covered with paraffin oil to prevent evaporation of water during measurements.

Viscoelastic behaviour was investigated using SAOS testing. At first, stress sweep tests were performed both on suspensions and on gels in order to identify the region of linear viscoelasticity. The stress range applied was of 0.1$1,000 \mathrm{~Pa}$ at several frequencies $(0.1,1$ and $100 \mathrm{~Hz})$. Temperature, time and frequency sweep tests were set up inside the viscoelastic region, in a frequency range of 0.1$10 \mathrm{~Pa}$ for aqueous flour suspensions and $0.1-100 \mathrm{~Pa}$ for gels. Preliminary gap selection was also made from the stress sweep curves, traced with the following gap range $-0.250,0.500,0.750$ or $1.000 \mathrm{~mm}$. The determinations were replicated at least three times. The best repeatability curves were those traced with a $0.500 \mathrm{~mm}$ gap.

Thereafter, aqueous flour suspensions were placed on the measuring device at $20^{\circ} \mathrm{C}$ and heated to $90^{\circ} \mathrm{C}$ at $2{ }^{\circ} \mathrm{C} / \mathrm{min}$. After heating, time sweep tests were conducted at $90^{\circ} \mathrm{C}$ for $60 \mathrm{~min}$ at $0.1 \mathrm{~Hz}$. After thermal treatment, samples were cooled down to $5{ }^{\circ} \mathrm{C}$ at $1{ }^{\circ} \mathrm{C} / \mathrm{min}$. All temperature sweep tests were performed at $0.1 \mathrm{~Hz}$. A constant shear stress $(2 \mathrm{~Pa})$ within the linear viscoelastic region of the materials was used in all aforementioned tests. After cooling, time sweep tests were conducted at $5{ }^{\circ} \mathrm{C}$, during a reasonable period of time $(60 \mathrm{~min})$ at $1 \mathrm{~Hz}$. After this period, without disturbing the gel, frequency sweeps were carried out at $20{ }^{\circ} \mathrm{C}$, with oscillation frequencies over the range 0.01 to $100 \mathrm{~Hz}$. A constant shear stress (30 Pa) within the linear viscoelastic region of the gels was used in the two latter tests. All measurements were made at least in triplicate, and reproducible results were achieved.
Stability Measurements

The physical stability of studied gels was measured with the LUMiSizer $^{\circledR}$ (L.U.M. GmbH, Berlin, Germany), a new technique employing gravitational fields to accelerate the occurrence of instability phenomena such as sedimentation, flocculation or creaming (Xu et al. 2012). STEPTM (Spaceand Time-resolved Extinction Profiles) technology was used to measure the transmitted light intensity as a function of time and position, over the entire sample length. The evolution of the transmission profiles, i.e. of the position of the interface between the particle-free solution and the dispersion can yield information not only about the gel stability, but also about particle-particle hydrodynamic interactions and deformability. The measuring principle and the analytical procedure followed are described in detail in Glampedaki et al. (2012). The instrumental parameters used for the measurement were as follows-volume, $1.8 \mathrm{~mL}$ of dispersion; 4,000 rpm; experiment time, $8850 \mathrm{~s}$; time interval, $30 \mathrm{~s}$; temperature, $25{ }^{\circ} \mathrm{C}$. The experiments were performed at least in triplicate.

\section{Statistical Analysis}

Experimental data were analysed by means of one-factor analysis of variance. When the analysis of variance indicated differences among means, a Scheffe test was performed to differentiate means with $95 \%$ confidence $(p<0.05)$. All statistical treatments were done using PASW Statistics (v.18, IBM SPSS Statistics, New York, USA).

\section{Results and Discussion}

\section{Physicochemical Proximate Characterisation}

The proximate composition of flours used as raw materials for gels preparation is given in Table 1. The moisture content of studied flours was around $11.8 \pm 0.5 \%$ d.b.; the fat content

Table 1 Proximate physicochemical characteristics of chestnut flour (Cf), whole rice flour (Rw), Carolino rice flour (Rc) and Agulha rice flour (Ra)

\begin{tabular}{lllll}
\hline $\mathrm{a}$ & $\mathrm{Cf}$ & $\mathrm{Rw}$ & $\mathrm{Rc}$ & $\mathrm{Ra}$ \\
\hline Moisture content, \% & $11.5 \pm 0.2 \mathrm{a}$ & $11.7 \pm 0.1 \mathrm{a}$ & $12.0 \pm 0.2 \mathrm{a}$ & $11.6 \pm 0.3 \mathrm{a}$ \\
Fat, \% & $2.78 \pm 0.04 \mathrm{a}$ & $2.64 \pm 0.04 \mathrm{a}$ & $1.43 \pm 0.05 \mathrm{~b}$ & $1.50 \pm 0.07 \mathrm{~b}$ \\
Total dietary fibre, \% & $5.33 \pm 0.12 \mathrm{a}, \mathrm{b}$ & $5.56 \pm 0.14 \mathrm{a}$ & $2.57 \pm 0.09 \mathrm{c}$ & $5.08 \pm 0.10 \mathrm{~b}$ \\
Insoluble fibre, \% & $4.17 \pm 0.11 \mathrm{~b}$ & $4.65 \pm 0.12 \mathrm{a}$ & $0.59 \pm 0.08 \mathrm{c}$ & $3.98 \pm 0.09 \mathrm{~b}$ \\
Soluble fibre, \% & $1.16 \pm 0.06 \mathrm{~b}$ & $0.91 \pm 0.08 \mathrm{c}$ & $1.98 \pm 0.03 \mathrm{a}$ & $1.09 \pm 0.05 \mathrm{~b}, \mathrm{c}$ \\
Average particle size, $D_{\mathrm{w}}, \mu \mathrm{m}$ & $95.4 \pm 3.2 \mathrm{a}$ & $91.5 \pm 2.1 \mathrm{a}$ & $94.6 \pm 2.5 \mathrm{a}$ & $92.4 \pm 2.9 \mathrm{a}$
\end{tabular}

${ }^{\text {a }}$ Data are presented as mean \pm standard deviation. Data values in a row with different letters are significantly different at the $p \leq 0.05$ level. Percentages are given in flour basis, d.b. 
ranged from 1.43 to $2.78 \%$ d.b. and the total fibre content from 2.57 to $5.56 \%$ d.b. $\mathrm{Cf}(2.78 \%$ d.b.), and Rw (2.64\% d.b.) contained significantly larger fat amounts than Rc (1.43\% d.b.) and Ra (1.50\% d.b.), which can be explained taking into account the processing conditions since the latter have been polished. It can be seen that Rw (5.56\% d.b.) and Cf $(5.33 \%$ d.b.) presented the highest total dietary fibre content. Namely, this fibre is associated with stimulation of Bifidobacterium and Lactobacillus in the gut, decrease in cholesterol levels, reduction of the risk of cardiovascular diseases, positive regulation of insulin response and increase in anticancer mechanisms (Prosky 2000). It was also observed that Rc (2.57\% d.b.) exhibited the lowest content of total fibre in comparison to the other assayed flours. The fibre content of $\mathrm{Cf}$ varies notably depending on major or minor presence of internal tegument. In the case of Rw, Rc and Ra, the total fibre content differences can be explained taking into account that the chemical composition of flours can be influenced by milling, where the degree of removal of the outer rice layers causes a loss of fats and a large percentage of fibres, vitamins and minerals (Rosell and Marco 2008). The fat and total dietary fibre content of chestnut and rice flours were consistent with those previously reported by other authors (Miguelez et al. 2004; Marco and Rosell 2008; Correia et al. 2009; Moreira et al. 2012b).

Comparing insoluble fibre amounts, Rc values $(0.59 \%$ d.b.) were significantly lower than those obtained for the other flours, whereas Rw (4.65\% d.b.) exhibited the largest value. The soluble fibre found in Rc was $1.98 \%$ d.b., which is almost two times the soluble fibre amount identified in the other assayed flours. Differences in the composition of Rc when is compared with the other rice sources can be attributed to the variety and composition of the original Carolino rice grain. The differences in chemical compositions between tested flours may considerably influence pasting, rheological and gel texture properties (Charoenkul et al. 2011).

Other key point for the formulation of many kinds of products for different functionalities is the size of the particles. The average particle size, $D_{\mathrm{w}}$, of studied flours revealed no significant differences as shown in Table 1. In fact, the values of this parameter varied in a narrow range from 91.5 to $95.4 \mu \mathrm{m}$. Some authors have recommended these magnitudes of $D_{\mathrm{w}}$ for gluten-free flours in order to help in the water absorption improving the textural and rheological properties of the products (Onyango et al. 2009; Moreira et al. 2010). Latter work also showed relevant influence of particle size during heatingcooling operations.

\section{Swelling Power and Solubility}

The swelling power and solubility of $\mathrm{Cf}, \mathrm{Rw}, \mathrm{Rc}$ and $\mathrm{Ra}$ at different temperatures $\left(40-90^{\circ} \mathrm{C}\right)$ are depicted in Fig. 1a and b, respectively. The swelling power of assayed flours increased when the temperature was risen. This fact can be explained as follows: Starch granules absorbed some water in suspension at room temperature, but the amount of swelling was limited in intact granules. When heating the water suspension to progressively higher temperatures, very little happens, until a critical temperature is reached. At this point, the granule began to swell rapidly, a process termed gelatinisation. Granules in a population from the same sample do not all gelatinise at the same time but rather over a range of temperature. It was observed that all flours showed similar patterns with close swelling values, except for Rc which exhibited a cross-over point around $70{ }^{\circ} \mathrm{C}$. Above this temperature, the swelling power of Rc was
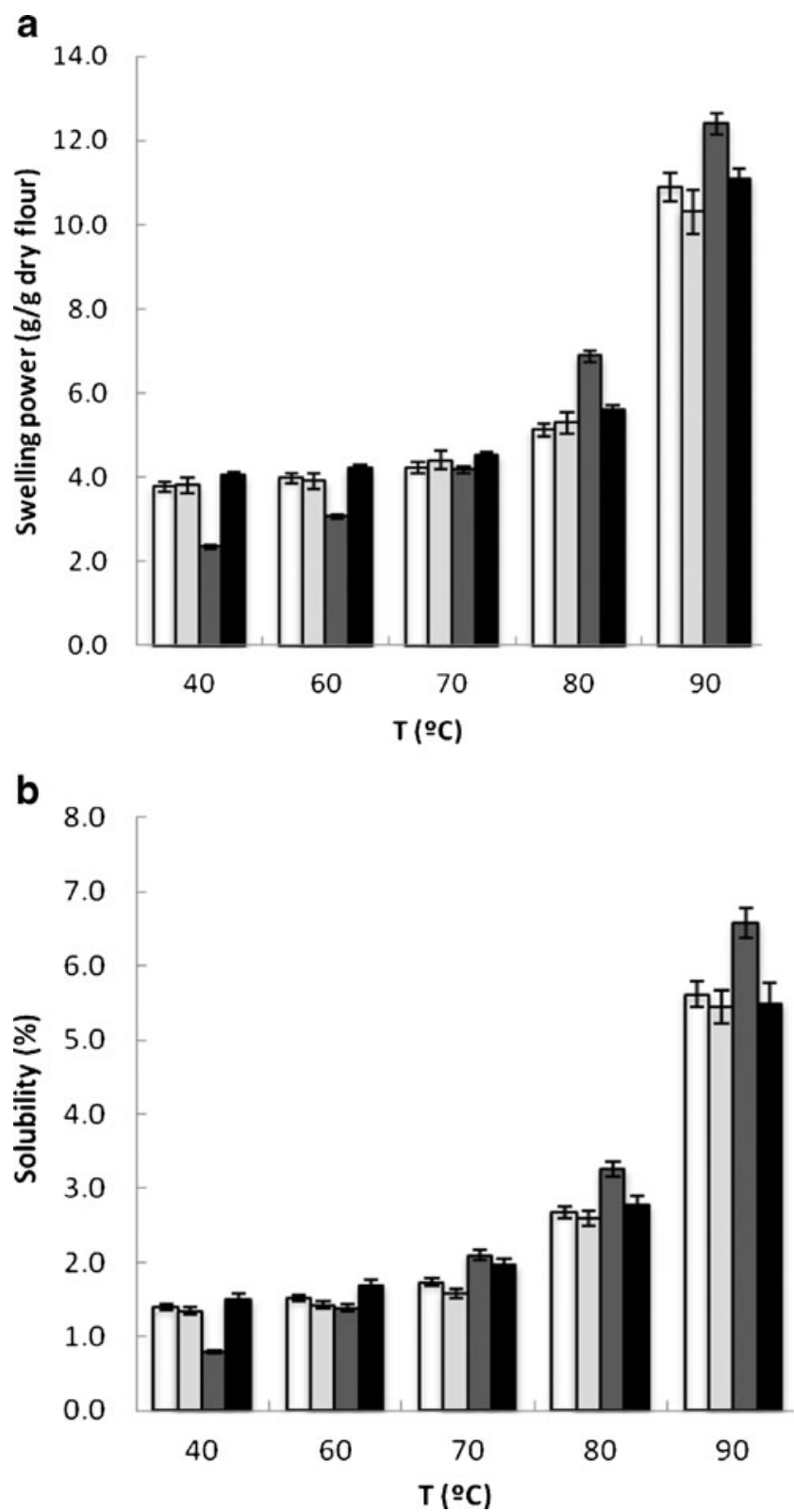

Fig. 1 Effect of temperature on a swelling and $\mathbf{b}$ solubility of studied flours. Symbols: white bars chestnut flour, Cf; light grey bars whole rice flour, Rw; dark grey bars Carolino rice flour, Rc; black bars Agulha rice flour, Ra 
larger than the other tested flours whereas the swelling values of Rc below $70^{\circ} \mathrm{C}$ were notably lower than that of $\mathrm{Cf}$, $\mathrm{Rw}$ and Ra. These results indicated that pregelatinised starch granules in Rc are more susceptible to water hydration involving stronger gelforming properties (Lai 2001). The increase in swelling power of flours at high temperature was previously related to the pasting results, being promoted the corresponding pasting temperatures (Takahashi et al. 2005). The results obtained in this work are in good agreement with the swelling power reported for chestnut flours (Correia and Beirao-da-Costa 2012) and rice flours (Takahashi et al. 2005). These authors found that the swelling power of native starches increased with increasing temperature which was more pronounced at temperatures above $70{ }^{\circ} \mathrm{C}$.

When starch is heated in presence of water to exceed gelatinisation temperature, the granules imbibe water, swell and some starch leaches into the solution. The solubility (Fig. 1b) values of studied flours were not significantly different, except for Rc which again showed some singularities. The average solubility of tested chestnut and rice flours indicated that Rc exhibited the highest solubility values above $70{ }^{\circ} \mathrm{C}$. There was a good correlation between the results achieved for swelling power and solubility of assayed flours. These solubility profiles were consistent with those observed in chestnut starch (Correia et al. 2012) and tuber and root starches (Gunaratne and Hoover 2002). Nevertheless, the magnitudes of the solubility obtained from $\mathrm{Cf}(\sim 6.0 \%)$ at $90{ }^{\circ} \mathrm{C}$ were considerably high when compared with values from chestnut starch ( 1.8\%) (Correia et al. 2012). The encountered values could be influenced by some factors, mainly the cross-linking level, as it is well known that solubility can increase with decreasing degree of crosslinking (Lan et al. 2008). Moreover, the presence of several components into the flour can compete by water (sugars or soluble fibres) or exert the reverse effect (insoluble fibres), modifying notably the solubility behaviour (Lai et al. 2011).

\section{Colour Measurements}

The colour parameters of gels prepared using $\mathrm{Cf}$ and $\mathrm{Rw}, \mathrm{Rc}$ or $\mathrm{Ra}$ at several ratios (Cf/Rf, 0/100, 20/80, 40/60, 50/50, $60 / 40,80 / 20$ and $100 / 0 \%$ ) with a total flour content of 20 (percent, $w / w$ ) are presented in Table 2 as representative examples of studied systems. The lightness, $\mathrm{L}^{*}$, and whiteness of $\mathrm{Cf}$ pure gels was significantly lower than those values obtained for Rf pure gels; subsequently, the redness, $\mathrm{a}^{*},(2.06)$ and the yellowness, $\mathrm{b}^{*},(10.98)$ of Cf pure gels were significantly higher than the data achieved for pure gels from $\mathrm{Rw}\left(\mathrm{a}^{*}=0.60, \mathrm{~b}^{*}=8.11\right), \operatorname{Rc}\left(\mathrm{a}^{*}=0.76, \mathrm{~b}^{*}=6.93\right)$ and $\mathrm{Ra}\left(\mathrm{a}^{*}=0.43, \mathrm{~b}^{*}=3.94\right)$. These results are consistent with the work reported by Takahashi et al. (2005), who also identified colour change (increased $a^{*}$ and $b^{*}$ values) of japonica milled rice flour heat-treated. It can be noticed that
Cf pure gels were the darkest with whiteness values of 24.98 followed by pure gels from Rw (46.39), Ra (51.64) and Rc (56.43). Overall, the total content of flour has no impact in terms of colour. When these gels were subjected to several thermal $\left(70,80,90^{\circ} \mathrm{C}\right)$ and time $(15,30$ and $60 \mathrm{~min})$ treatments, it was observed that as temperature and time processing rise during the preparation of the gels, pure gels become moderately darker (lower $L^{*}$ values), probably owing to a larger extension of caramelisation and Maillard reaction. In fact, it was also noticed that the colour intensity (chroma) of pure gels decreased with time/temperature treatment. Similar results were reported for chestnut flours when the effect of drying temperature of chestnut fruits was assessed (Correia et al. 2009).

The colour parameters of tested gels were notably affected by $\mathrm{Cf} / \mathrm{Rf}$ ratio (Table 2). Lightness and whiteness values decreased significantly with increasing $\mathrm{Cf}$ amount; subsequently, yellowness, redness and colour intensity values increased. The magnitudes of these parameters increased significantly with increasing $\mathrm{Cf}$ until $\mathrm{Cf} / \mathrm{Rf}$ around 50/50 \%. Above this ratio, aforementioned colour parameters did not present significant differences. Specifically, the colour parameters showed that $\mathrm{Cf} / \mathrm{Rc}$ gels were the least dark followed by $\mathrm{Cf} / \mathrm{Ra}$ and $\mathrm{Cf} / \mathrm{Rw}$ independently of the assayed ratio. The obtained parameters values are within the same range that those previously reported for several rice flours (Song and Shin 2007).

\section{Texture Measurements}

Macrostructure of the gels was evaluated in terms of texture using the TPA. Firmness values of selected gels prepared with $\mathrm{Cf}$, at several concentrations, using different processing conditions are depicted in Fig. 2. Firmness values of all studied gels produced at concentrations between 20 and $30 \%$ (d.b.) were similar to those obtained for commercially available desserts (Batista et al. 2002). The magnitude of this parameter increased significantly with increasing $\mathrm{Cf}$ content. The temperature and heating time used for the gels preparation also modified the texture, giving a slight rise to firmness values. Specifically, the magnitude of the firmness of gels prepared at $90{ }^{\circ} \mathrm{C}$ was moderately higher than those data achieved at $80{ }^{\circ} \mathrm{C}$ for the same heating time, except for gels at $20 \%$ (d.b.) where no significant differences were found. Similar tendencies to temperature were identified for heating time (30 and $60 \mathrm{~min}$ ). It was also noticed that firmness values of $\mathrm{Cf}$ pure gels prepared at $80{ }^{\circ} \mathrm{C}$ for 60 min were not statistically different from those prepared at $90^{\circ} \mathrm{C}$ for $30 \mathrm{~min}$. When lower temperatures $\left(70^{\circ} \mathrm{C}\right)$ and heating times $(15 \mathrm{~min})$ were used to prepare the gels a considerable reduction in firmness values from 0.042 to $0.085 \mathrm{~N}$ was found (not shown). Similar results were found for Rf pure gels.

Figure 3 shows the firmness values obtained for the mixed $\mathrm{Cf} / \mathrm{Rf}$ gels selected as representative examples of 
Table $2 \mathrm{~L}^{*}, \mathrm{a}^{*}$ and $\mathrm{b}^{*}$ colour values, whiteness and chroma of gels prepared using chestnut flour (Cf) and each of the three rice flours $(\mathrm{Rw}, \mathrm{Rc}, \mathrm{Ra})$ at several ratios $(\%)(\mathrm{Cf} / \mathrm{Rf}, 0 / 100,20 /$ $80,40 / 60,50 / 50,60 / 40,80 / 20$ and $100 / 0$ ) with a total flour content of $20 \%, w / w$

${ }^{a}$ Data are presented as mean \pm standard deviation. Data values in a column with different letters are significantly different at the $p \leq 0.05$ level

\begin{tabular}{|c|c|c|c|c|c|}
\hline Samples ${ }^{\mathrm{a}}$ & $\mathrm{L}^{*}$ & $a^{*}$ & $\mathrm{~b}^{*}$ & Whiteness & Chroma \\
\hline \multicolumn{6}{|l|}{$\mathrm{Cf} / \mathrm{Rw}$} \\
\hline $0 / 100$ & $47.01 \pm 0.20 \mathrm{~d}$ & $0.60 \pm 0.05 \mathrm{~g}$ & $8.11 \pm 0.13 \mathrm{e}$ & $46.39 \pm 0.23 \mathrm{~d}$ & $8.13 \pm 0.04 \mathrm{e}$ \\
\hline $20 / 80$ & $39.55 \pm 0.31 \mathrm{~h}$ & $0.87 \pm 0.04 \mathrm{f}$ & $8.46 \pm 0.20 \mathrm{~d}, \mathrm{e}$ & $38.95 \pm 0.32 \mathrm{~h}$ & $8.50 \pm 0.02 \mathrm{~d}, \mathrm{e}$ \\
\hline $40 / 60$ & $37.88 \pm 0.11 \mathrm{i}$ & $1.63 \pm 0.08 \mathrm{~b}, \mathrm{c}$ & $8.71 \pm 0.12 \mathrm{~d}$ & $37.25 \pm 0.15 \mathrm{i}$ & $8.86 \pm 0.03 \mathrm{~d}$ \\
\hline $50 / 50$ & $34.31 \pm 0.22 \mathrm{j}$ & $1.66 \pm 0.05 \mathrm{~b}, \mathrm{c}$ & $9.43 \pm 0.21 \mathrm{c}, \mathrm{d}$ & $33.62 \pm 0.34 j$ & $9.57 \pm 0.11 \mathrm{c}, \mathrm{d}$ \\
\hline $60 / 40$ & $33.16 \pm 0.04 \mathrm{k}$ & $1.96 \pm 0.06 \mathrm{a}$ & $9.52 \pm 0.11 \mathrm{c}, \mathrm{d}$ & $32.46 \pm 0.12 \mathrm{k}$ & $9.72 \pm 0.05 \mathrm{c}, \mathrm{d}$ \\
\hline $80 / 20$ & $27.50 \pm 0.121$ & $2.01 \pm 0.11 \mathrm{a}$ & $9.73 \pm 0.11 \mathrm{c}$ & $26.82 \pm 0.151$ & $9.98 \pm 0.21 \mathrm{c}$ \\
\hline $100 / 0$ & $25.68 \pm 0.31 \mathrm{~m}$ & $2.06 \pm 0.12 \mathrm{a}$ & $10.98 \pm 0.05 \mathrm{a}$ & $24.98 \pm 0.21 \mathrm{~m}$ & $11.17 \pm 0.04 \mathrm{a}$ \\
\hline \multicolumn{6}{|l|}{$\mathrm{Cf} / \mathrm{Rc}$} \\
\hline $0 / 100$ & $56.14 \pm 0.41 \mathrm{a}$ & $0.76 \pm 0.04 \mathrm{f}$ & $6.93 \pm 0.31 \mathrm{f}$ & $56.43 \pm 0.54 a$ & $6.93 \pm 0.21 \mathrm{f}$ \\
\hline $20 / 80$ & $50.03 \pm 0.22 \mathrm{c}$ & $1.56 \pm 0.06 \mathrm{c}, \mathrm{d}$ & $8.95 \pm 0.42 \mathrm{~d}$ & $49.21 \pm 0.33 c$ & $9.08 \pm 0.11 \mathrm{~d}$ \\
\hline $40 / 60$ & $47.09 \pm 0.31 \mathrm{~d}$ & $1.75 \pm 0.08 \mathrm{~b}$ & $10.08 \pm 0.21 \mathrm{c}$ & $46.11 \pm 0.56 \mathrm{~d}$ & $10.23 \pm 0.14 \mathrm{c}$ \\
\hline $50 / 50$ & $46.83 \pm 0.11 \mathrm{~d}$ & $2.03 \pm 0.06 \mathrm{a}$ & $10.22 \pm 0.22 \mathrm{~b}, \mathrm{c}$ & $45.82 \pm 0.29 \mathrm{~d}$ & $10.42 \pm 0.04 \mathrm{~b}$ \\
\hline $60 / 40$ & $43.59 \pm 0.31 \mathrm{~g}$ & $2.04 \pm 0.09 \mathrm{a}$ & $10.46 \pm 0.03 b$ & $42.59 \pm 0.31 \mathrm{~g}$ & $10.66 \pm 0.03 b$ \\
\hline $80 / 20$ & $40.24 \pm 0.22 \mathrm{~h}$ & $2.05 \pm 0.05 \mathrm{a}$ & $10.56 \pm 0.05 b$ & $39.28 \pm 0.24 \mathrm{~h}$ & $10.76 \pm 0.03 b$ \\
\hline $100 / 0$ & $25.68 \pm 0.31 \mathrm{~m}$ & $2.06 \pm 0.12 \mathrm{a}$ & $10.98 \pm 0.05 \mathrm{a}$ & $24.98 \pm 0.21 \mathrm{~m}$ & $11.17 \pm 0.04 \mathrm{a}$ \\
\hline \multicolumn{6}{|l|}{$\mathrm{Cf} / \mathrm{Ra}$} \\
\hline $0 / 100$ & $52.61 \pm 0.31 \mathrm{~b}$ & $0.43 \pm 0.04 \mathrm{~h}$ & $3.94 \pm 0.21 \mathrm{~g}$ & $51.64 \pm 0.12 b$ & $3.96 \pm 0.11 \mathrm{~g}$ \\
\hline $20 / 80$ & $44.75 \pm 0.11 \mathrm{e}$ & $1.18 \pm 0.08 \mathrm{e}$ & $8.64 \pm 0.34 d$ & $44.07 \pm 0.21 \mathrm{e}$ & $8.72 \pm 0.14 \mathrm{~d}$ \\
\hline $40 / 60$ & $44.17 \pm 0.08 f$ & $1.43 \pm 0.03 \mathrm{~d}$ & $10.11 \pm 0.05 \mathrm{c}$ & $43.25 \pm 0.13 f$ & $10.20 \pm 0.03 \mathrm{c}$ \\
\hline $50 / 50$ & $44.05 \pm 0.02 f$ & $1.77 \pm 0.06 b$ & $10.35 \pm 0.11 b, c$ & $43.07 \pm 0.04 \mathrm{f}$ & $10.50 \pm 0.02 b$ \\
\hline $60 / 40$ & $40.21 \pm 0.12 \mathrm{~h}$ & $1.78 \pm 0.02 b$ & $10.86 \pm 0.09 \mathrm{a}$ & $39.20 \pm 0.13 \mathrm{~h}$ & $11.00 \pm 0.04 \mathrm{a}$ \\
\hline $80 / 20$ & $38.42 \pm 0.07 i$ & $1.87 \pm 0.01 \mathrm{~b}$ & $10.93 \pm 0.23 a$ & $37.43 \pm 0.21 \mathrm{i}$ & $11.09 \pm 0.01 \mathrm{a}$ \\
\hline $100 / 0$ & $25.68 \pm 0.31 \mathrm{~m}$ & $2.06 \pm 0.12 \mathrm{a}$ & $10.98 \pm 0.05 \mathrm{a}$ & $24.98 \pm 0.21 \mathrm{~m}$ & $11.17 \pm 0.04 \mathrm{a}$ \\
\hline
\end{tabular}

the assayed systems. All $\mathrm{Cf} / \mathrm{Rf}$ gels showed a drop in the firmness values with increasing $\mathrm{Cf}$ content. $\mathrm{Cf} / \mathrm{Rf}$ gels at

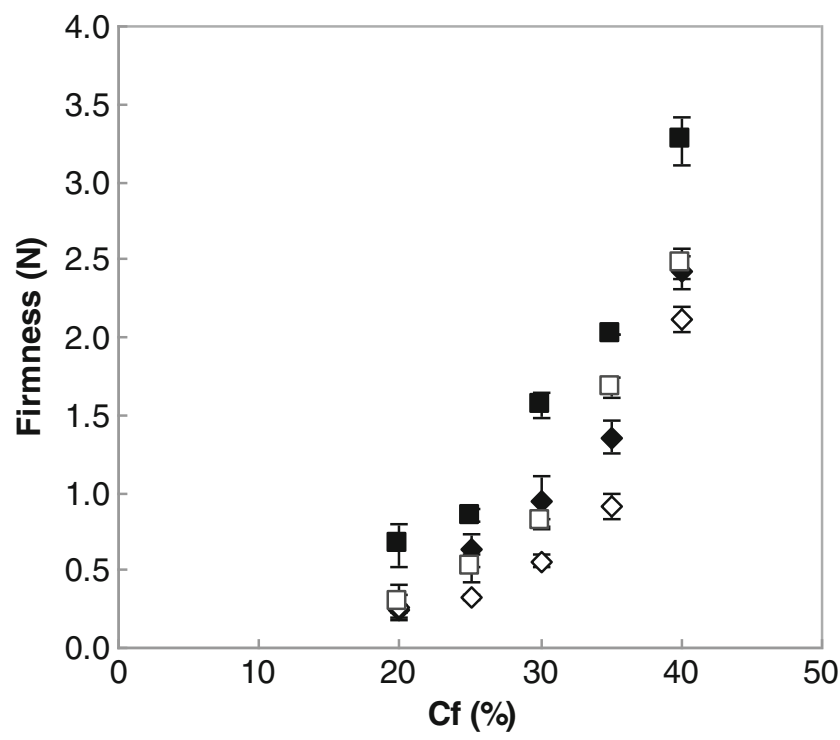

Fig. 2 Firmness values of gels prepared with chestnut flour, Cf, at several concentrations using different processing conditions. Symbols: closed $90{ }^{\circ} \mathrm{C}$, open $80^{\circ} \mathrm{C}$, diamonds $30 \mathrm{~min}$, squares $60 \mathrm{~min}$
$30 \%$ d.b. of total flour content exhibited higher firmness values than the $20 \%$ d.b. ones and are outside the range found for commercial gelled desserts (Batista et al. 2002). One can see that in terms of firmness $\mathrm{Cf} / \mathrm{Rf}(0 / 100)$ gels at $30 \%$ (d.b.) were comparable to $\mathrm{Cf} / \mathrm{Rf}(100 / 0)$ gels at $20 \%$ (d.b.). It was also noteworthy that systems with larger fibre content (Table 1, Cf/Rw gels) presented higher firmness values. These results are consistent with those previously found on dough cookies production enriched with fibre where a general increase of texture parameters was recorded with increasing fibre levels (Piteira et al. 2006). At the same total flour content, $\mathrm{Cf} / \mathrm{Rw}$ and $\mathrm{Cf} / \mathrm{Ra}$ gels showed close values of firmness. $\mathrm{Cf} / \mathrm{Rc}$ gels presented the lowest values, even though its firmness is inside the range of variation of this characteristic for commercial desserts. The highest differences between $\mathrm{Cf} / \mathrm{Rc}$ gels and $\mathrm{Cf} / \mathrm{Rw}$ or $\mathrm{Cf} / \mathrm{Ra}$ were achieved at ratios of $20 / 80$ where the proportion of $\mathrm{Rc}$ is higher and, therefore the fibre content differences as well. These texture studies suggested that for simple systems, a total flour content of $30 \%$ for $\mathrm{Cf}$ is comparable in texture with those of $20 \%$ for Rf. For this flour content, the amount of dietary fibre on the final gels is around $1.5 \%$ that can be considered an additional benefit to these formulations. 
Fig. 3 Firmness values of gels prepared using chestnut flour, $\mathrm{Cf}$, and each of the three rice flours (Rw, Rc, Ra) at several ratios (\%) (Cf/Rf, 0/100, 20/80, $40 / 60,50 / 50,60 / 40,80 / 20$ and 100/0). Symbols: closed total flour content of $30 \% \mathrm{w} / \mathrm{w}$, open total flour content of $20 \% \mathrm{w} / \mathrm{w}$, circles $\mathrm{Cf} / \mathrm{Rw}$, triangles $\mathrm{Cf} / \mathrm{Rc}$, squares $\mathrm{Cf} / \mathrm{Ra}$

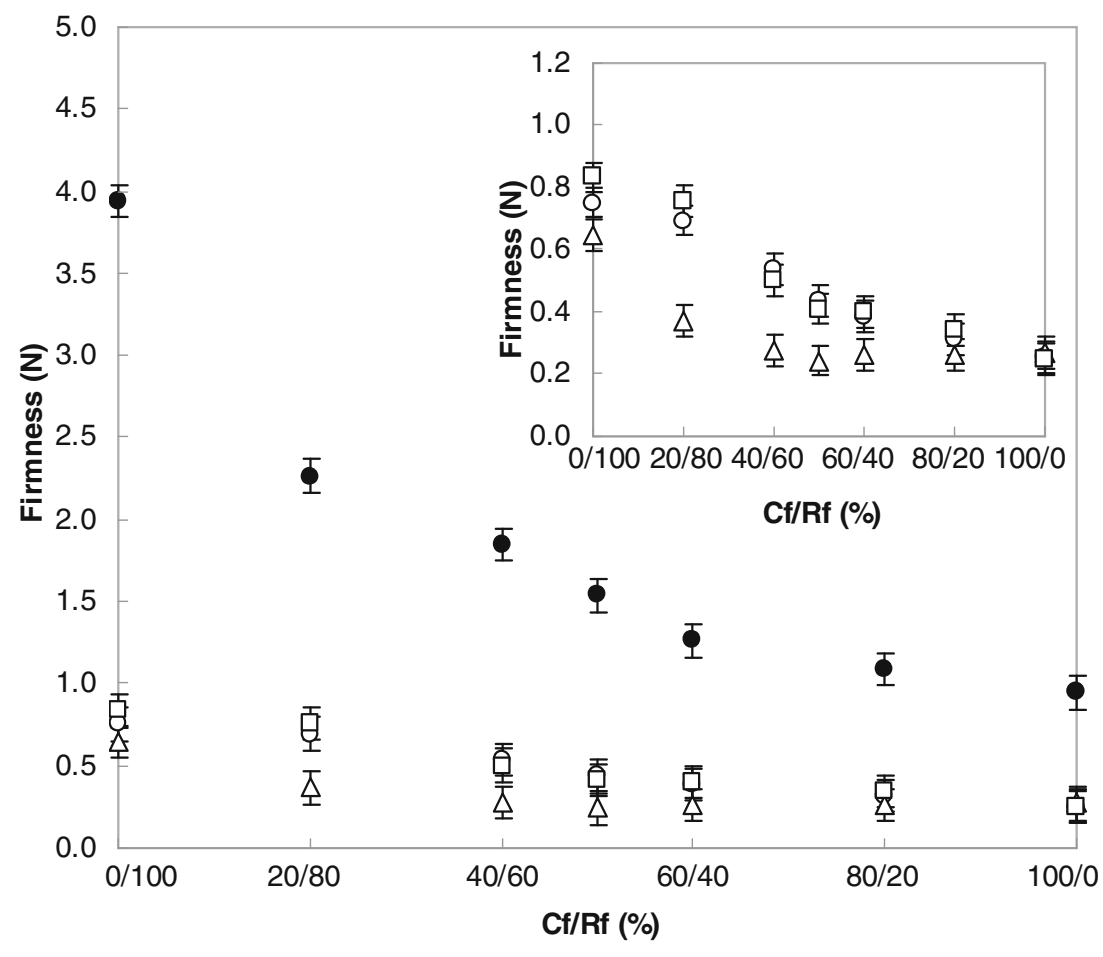

Thermorheological Measurements

Figure 4 a shows the evolution of storage $\left(G^{\prime}\right)$ and loss $\left(G^{\prime \prime}\right)$ moduli, with temperature, for selected pure gels from $\mathrm{Cf}$, Rw, Rc and Ra. All studied samples exhibited G' larger than $G^{\prime \prime}$ (about one decade) in the whole temperature range. During the initial heating, both moduli remained practically constant. The first inflection point corresponding to the initial gelatinisation temperature $\left(T_{0}\right)$ was identified around $60 \pm 1.5^{\circ} \mathrm{C}$, except for Rc where $T_{0}$ started earlier $(45.1 \pm$ $\left.1.2{ }^{\circ} \mathrm{C}\right)$. These results could be related to the lower total fibre content of Rc. In fact, a delay in the starch gelatinisation was previously described for fibre-enriched doughs (Santos et al. 2008; Moreira et al. 2012a). Thereafter, $G^{\prime}$ and $G^{\prime \prime}$ began to increase rapidly with increasing temperature reaching a peak corresponding to the final gelatinisation temperature $\left(T_{1}\right)$ around $73.0 \pm 1.8{ }^{\circ} \mathrm{C}$ for all samples. Once the gelatinisation temperature was reached, Rc gels seem to be the most thermostable (both moduli were constant up to $90{ }^{\circ} \mathrm{C}$ ). Furthermore, the thermal profiles on heating showed a similar pattern for all gels, except for Rc. Namely, this sample showed lower values (about one decade) of $\mathrm{G}^{\prime}$ and $\mathrm{G}^{\prime \prime}$ below $70^{\circ} \mathrm{C}$, exhibiting the weakest gel properties. However, above this temperature a cross-over point was observed, achieving the largest values of storage and loss moduli at the highest temperatures. The strongest gel network was rapidly formed upon heating above $70{ }^{\circ} \mathrm{C}$ for Rc gels. These results are in close agreement with those aforementioned for swelling measurements for the same samples (Fig. 1). The promotion on the gel properties can be also related to the largest amounts of soluble fibre present in Rc systems (Table 1). The starch gel properties can change significantly adding soluble polymers, even if the amount added was small. Many authors reported that water-soluble polymers can impact positively in the gel formation of some starches tending to show higher solubilised starch amounts (Cornejo-Villegas et al. 2010). Latter authors found that this behaviour is highly dependent on the assayed starch source.

In order to understand the role of each flour on the gel network of the assayed mixtures, cooling curves of pure gels, $\mathrm{Cf}$ and Rf, were obtained from 90 down to $5^{\circ} \mathrm{C}$. During the cooling process (Fig. 4b), the gel structure was moderately reinforced. When cooling down to $5{ }^{\circ} \mathrm{C}$, viscoelastic parameters $G^{\prime}$ and $G^{\prime \prime}$ increasing progressively, achieving larger values (around two times) at the lowest temperatures revealing a gel structure reinforcement. This effect is more clearly observed on $\mathrm{G}^{\prime}$ values. Again, no significant differences were identified between $\mathrm{Cf} 30 \%$ and Rf $20 \%$ gels. This pattern of structural development is consistent with the results previously reported by Nunes et al. (2006), where the moderate variation in $\mathrm{G}^{\prime}$ and $\mathrm{G}^{\prime \prime}$ during cooling of maize starch gels was explained by the combined effect of the gradual change of the swollen granules and the formation of an amylose gel network. Similar results have been also found for other starch pastes (Miles et al. 1985).

When the gels are maintained at low temperatures for a long time, at slow cooling rates, there is more time for dynamic equilibrium of the gel network to take place, i.e. some gel structure maturation, leading to a more structured network on cooling. The maturation kinetics of studied gels (Fig. 4c) 
a

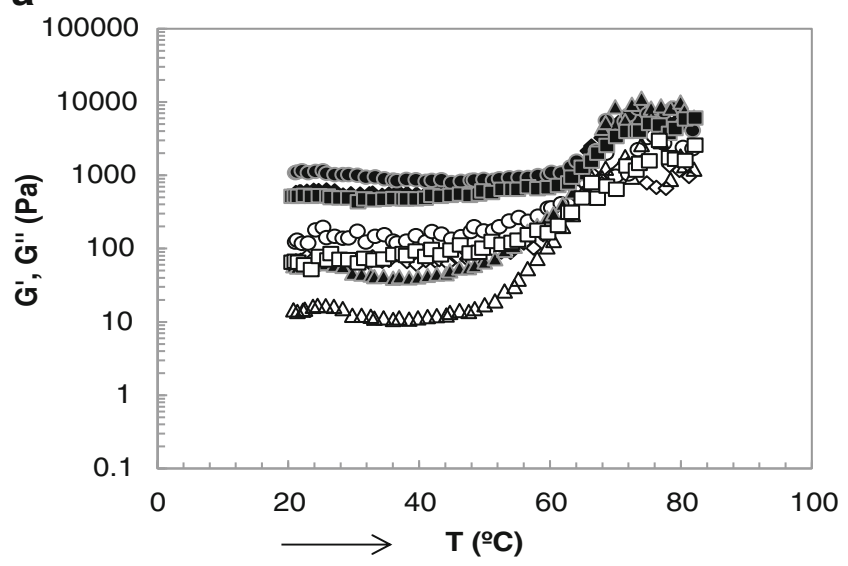

C

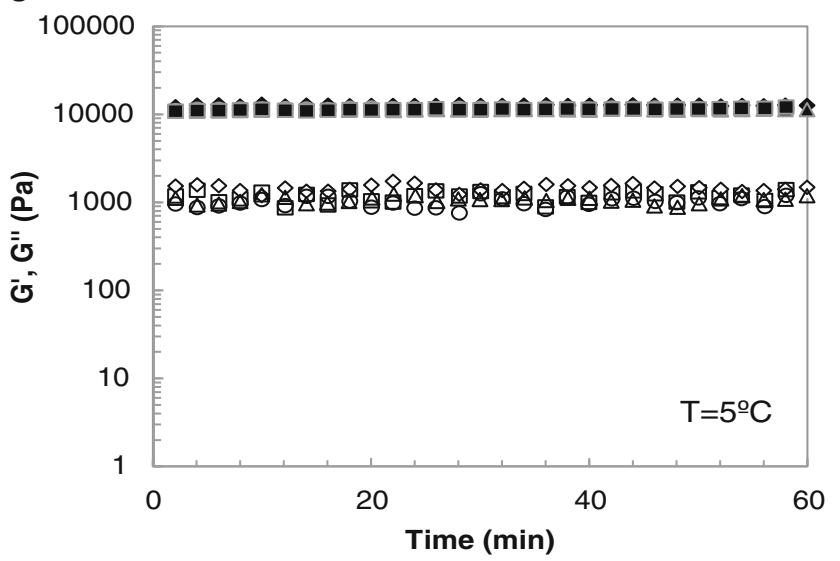

Fig. 4 Thermorheological measurements of aqueous suspensions prepared with chestnut flour $(\mathrm{Cf})$; whole rice flour $(\mathrm{Rw})$; Carolino rice flour $(\mathrm{Rc})$ and Agulha rice flour (Ra): a temperature sweep (20 to $90{ }^{\circ} \mathrm{C}$ at $2{ }^{\circ} \mathrm{C} / \mathrm{min}$ ); b temperature sweep ( 90 to $5^{\circ} \mathrm{C}$ at $1{ }^{\circ} \mathrm{C} / \mathrm{min}$ ); c

was monitored through the evolution with time of the storage and loss moduli at $5{ }^{\circ} \mathrm{C}$. Both moduli remained stable during 60 min maturation, with steady values for $\mathrm{G}^{\prime}$ around 1.2 $10^{4} \mathrm{~Pa}$ and for $\mathrm{G}^{\prime \prime}$ around $1.310^{3} \mathrm{~Pa}$. Again, no statistical differences were found between the four systems. It is clear that these gels reached a stable and fully developed structure within the time of the experiment. The short time necessary to give stable gel structure can be seen as an important advantage from an industrial point of view. The cooling and maturation behaviour exhibited is typical of biopolymer gelation. It is usually observed that $\mathrm{G}^{\prime}$ and $\mathrm{G}^{\prime \prime}$ increasing rapidly at first and then more slowly, although this pattern of structural development diverges for different biopolymers (Nunes et al. 2006).

Mechanical spectra of these gels, obtained at the end of the run at $5{ }^{\circ} \mathrm{C}$, are depicted in Fig. $4 \mathrm{~d}$. All samples exhibited a typical strong gel spectrum, i.e. G' was always larger than $\mathrm{G}^{\prime \prime}$, at about one decade, and are both almost frequency independent. This behaviour is according to the solid behaviour identified for rice flour (Marco and Rosell 2008) and chestnut
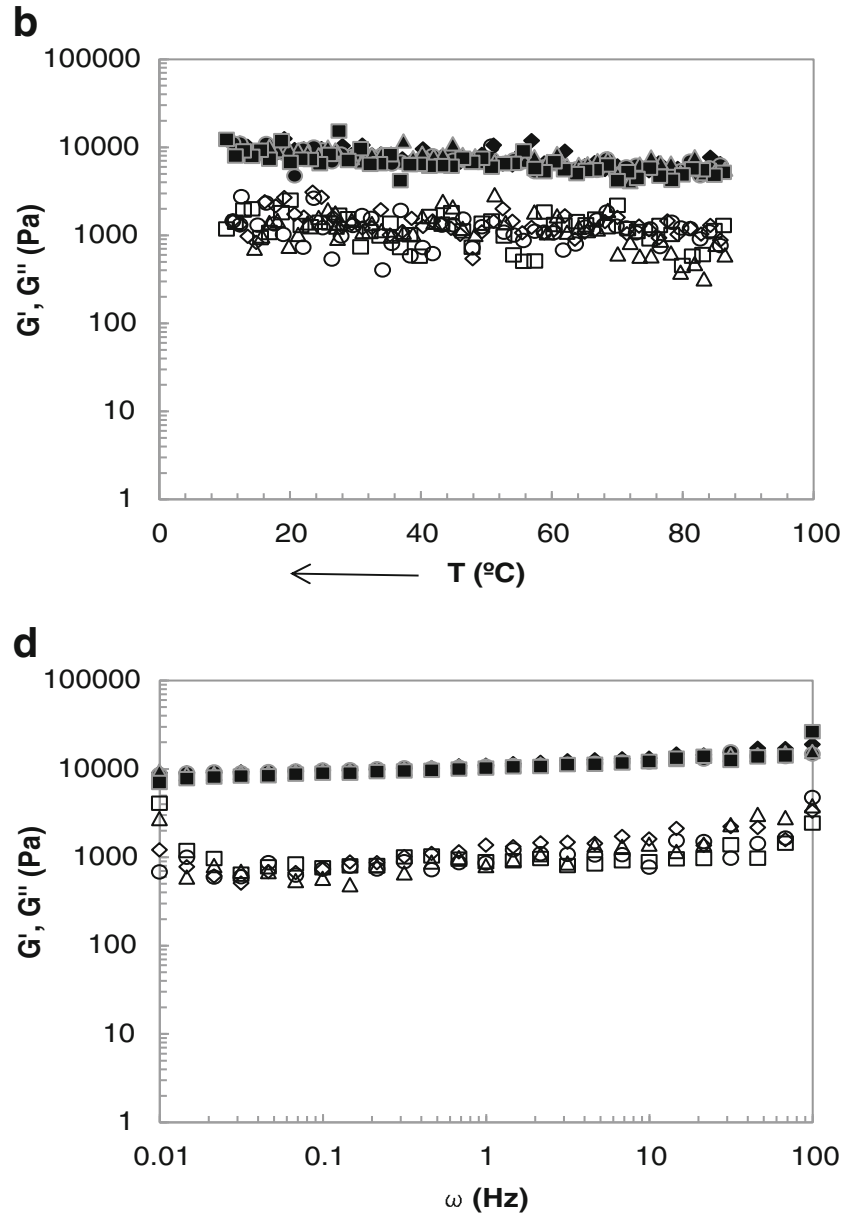

time sweep $\left(5^{\circ} \mathrm{C}\right)$; $\mathbf{d}$ frequency sweep $\left(20^{\circ} \mathrm{C}\right)$. Symbols: diamonds $\mathrm{Cf}$ $30 \%(w / w)$, circles Rw $20 \%(w / w)$, triangles Rc $20 \%(w / w)$, squares Ra $20 \%(w / w)$, closed storage modulus $\left(\mathrm{G}^{\prime}\right)$ open loss modulus $\left(\mathrm{G}^{\prime \prime}\right)$

flour pastes (Moreira et al. 2010, 2012b). The linear viscoelastic data for all studied gels are qualitatively similar, without significant changes in the values of G' and G" throughout all tested angular frequency range. The output data obtained from small deformation rheology are in close agreement with those found from large deformation test (TPA) of the same gels, where pure $\mathrm{Cf}$ gels at $30 \%$ indicated comparable properties to Rf pure gels at $20 \%$.

\section{Stability Measurements}

During formulation of new products the understanding of dispersion properties is a key factor in order to obtain the desired stability, textural and rheological properties. Taking into account that the gels under study are intended for food products, studying their storage stability was considered essential. The separation kinetics for pure gels from Cf, $\mathrm{Rw}, \mathrm{Rc}$ and Ra were investigated through light transmission under centrifugation at $25{ }^{\circ} \mathrm{C}$. Analysing the transmission 
A

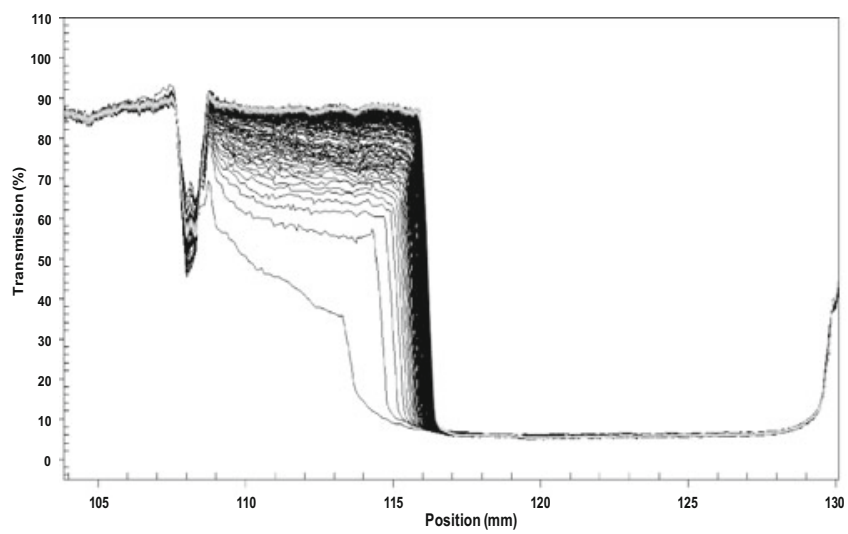

C

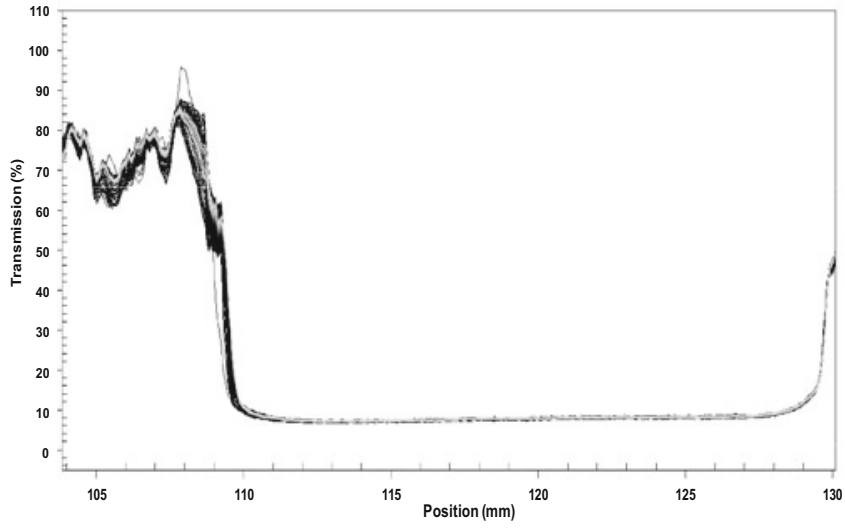

B

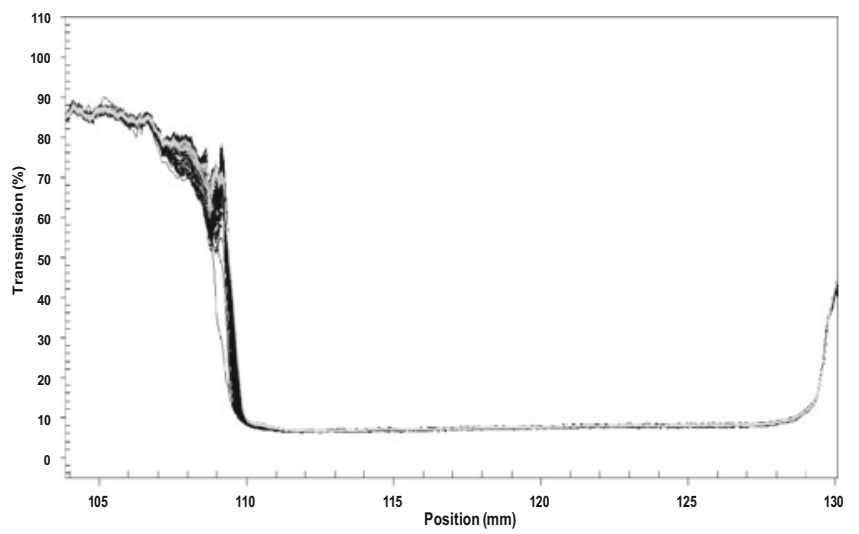

D

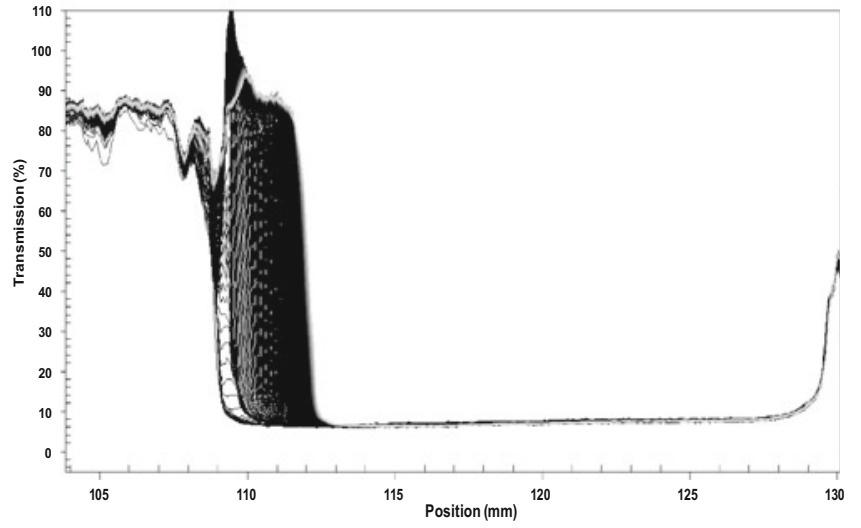

Fig. 5 Transmittance profiles of gels prepared using: a chestnut flour (Cf) at $30 \%$ of total flour content and b whole rice flour (Rw); c Carolino rice flour (Rc) and d Agulha rice flour (Ra) at $20 \%$ of total flour content at $25{ }^{\circ} \mathrm{C}$

profiles (Fig. 5a-d), it was observed that sedimentation occurred for gels prepared using $\mathrm{Cf}$ and $\mathrm{Ra}$ after LUMiSizer ${ }^{\circledR}$ centrifugation. The integration graphs showed the percentage of light absorbance per second (the sedimentation rate) which is correlated to the stability of the samples: the higher the sedimentation rate, the lower the stability (Glampedaki et al. 2012). Namely, the sedimentation rates (micrometer per second) were 0.51 for $\mathrm{Cf}, 0.43$ for $\mathrm{Ra}, 0.08$ for $\mathrm{Rw}$ and 0.06 for Rc, showing the highest stability for the latter sample. The corresponding instability indexes were 0.59 for $\mathrm{Cf}, 0.23$ for $\mathrm{Ra}, 0.03$ for $\mathrm{Rw}$ and 0.02 for Rc, where it can clearly observed that Rc gels showed the lowest values for this parameter, and thus the highest stability. It was also noticed that $\mathrm{Cf}$ and Ra gels exhibited an initial loss of stability, remaining practically constant after $500 \mathrm{~s}$. Even so, the achieved stability values are within those reported for other food systems (Xu et al. 2012).

In order to analyse the stability of the gels in the long term, it is necessary to know the time at which the separation of the sample can occur, being essential to define a criterion limit. In this case, it was assumed that the gels could be unstable if there was a separate layer of liquid (syneresis) with a thickness of
$1 \mathrm{~mm}$. At these conditions, one can calculate that gels from Rc can be maintained stables for at least 207 days; the same order of value is expected for gels of Rw. This period of time was reduced to 53 days in the case of Ra gels and in the same manner to 47 days for $\mathrm{Cf}$ gels. These periods of time are a relative measurement of the gel stability and are the time necessary to obtain a separate layer of liquid with a thickness of $1 \mathrm{~mm}$. The results above give more information than the thermorheological data achieved about the stability of the $\mathrm{Cf}$ and Rf gels.

\section{Conclusions}

This work demonstrated that gluten-free gels can be produced from Cf, Rw and Ra. They all exhibited similar patterns whereas those prepared with Rc showed particular properties. Texture characterisation indicated that formulations prepared using blends from $\mathrm{Cf}$ at $30 \%$ and $\mathrm{Rf}$ at $20 \%$ can be an interesting alternative to obtain gluten-free gelled products, with subsequent multiple advantages from the nutritional point of view. Although all systems presented 
stable and strong gel properties, stability tests allowed concluding that gels from $\mathrm{Rc}$ and $\mathrm{Rw}$ present an industrial advantage over the other formulations, since the stability is four times larger. Thus, besides the present data obtained only from rheological measurements, it is obviously necessary to take into account information from other methods, in order to understand the stability of these gels. The effect of other ingredients relevant for consumer acceptance (e.g. sugar, flavour, etc.) on the texture, rheology, stability and sensory characteristics of the selected gels has been investigated in detail in a parallel work. These gels can be an interesting product for the gluten-free products market and can provide additional economic value to wastes or byproducts coming from chestnut and rice processing industry.

Acknowledgements The authors wish to express their gratitude to the staff of Dias de Sousa for the stability analyses using LUMiSizer ${ }^{\mathbb{R}}$ and STEP ${ }^{\mathrm{TM}}$ technique. We also wish to thank to Novarroz (Portugal), who kindly provided rice materials.

\section{References}

AOAC. (1996). Official Methods of Analysis (16th ed.). Washington, USA: Association of Official Analytical Chemistry.

ASAE Standards (1995) S319.2: Methods for determining and expressing fineness of feed materials by sieving. Michigan, USA: American Society of Agricultural Engineers.

Bourne, M. (2002). Food Texture and Viscosity: Concept and Measurement. London, UK: Academic Press.

Batista, P., Nunes, M. C., \& Sousa, I. (2002). Physical characterisation of commercial dairy desserts. In F. Martinez Boza, A. Guerrero, P. Partal, J. Franco, \& J. Munoz (Eds.), Progress in Rheology: Theory and Applications. Spain: Publicaciones Digitales.

Borges, O. P., Carvalho, J. S., Correia, P. R., \& Silva, A. P. (2007). Lipid and fatty acid profiles of Castanea sativa Mill. chestnuts of 17 native Portuguese cultivars. Journal of Food Composition and Analysis, 20, 80-89.

Brites, C., Trigo, M. J., Santos, C., Collar, C., \& Rosell, C. M. (2008). Maize based gluten-free bread: Influence of processing parameters on sensory and instrumental quality. Food Bioprocess Technology, 3, 707-715.

Charoenkul, N., Uttapap, D., Pathipanawat, W., \& Takeda, Y. (2011). Physicochemical characteristics of starches and flours from cassava varieties having different cooked root textures. LWT- Food Science and Technology, 44, 1774-1781.

Collado, L. S., \& Corke, H. (2003). Starch properties and functionalities. In G. Kaletunc \& K. J. Breslauer (Eds.), Characterization of Cereals and Flours: Properties, Analysis and Applications, Chapter 15. New York, USA: Marcel Dekker.

Cornejo-Villegas, M. A., Acosta-Osorio, A. A., Rojas-Molina, I., Gutiérrez-Cortéz, E., Quiroga, M. A., Gaytán, M., et al. (2010). Study of the physicochemical and pasting properties of instant corn flour added with calcium and fibers from nopal powder. Journal of Food Engineering, 96, 401-409.

Correia, P., \& Beirao-da-Costa, M. L. (2012). Effect of drying temperatures on starch-related functional and thermal properties of chestnut flours. Food and Bioproducts Processing, 90, 284-294.

Correia, P., Leitão, A., \& Beirao-da-Costa, M. L. (2009). The effect of drying temperatures on morphological and chemical properties of dried chestnut flours. Journal of Food Engineering, 90, 325-332.
Correia, P., Nunes, M. C., \& Beirao-da-Costa, M. L. (2012). The effect of starch isolation method on physical and functional properties of Portuguese nuts starches. I. Chestnuts (Castanea sativa Mill. Var. Matainha and Longal) fruits. Food Hydrocolloids, 27, 256-263.

Demirkesen, I., Mert, B., Sumnu, G., \& Sahin, S. (2010). Utilization of chestnut flour in gluten-free bread formulations. Journal of Food Engineering, 101, 329-336.

Funami, T., Kataoka, Y., Noda, S., Hiroe, M., Ishihara, S., \& Asai, I. (2008). Functions of fenugreek gum with various molecular weights on the gelatinization and retrogradation behaviors of corn starch-2: Characterizations of starch and investigations of corn starch/fenugreek gum composite system at a relatively low starch concentration; $5 w / v \%$. Food Hydrocolloids, 22, 777-787.

Franco, J., Raymundo, A., Sousa, I., \& Gallegos, C. (1998). Influence of processing variables on the rheological and textural properties of lupin protein-stabilized emulsions. Journal of Agricultural and Food Chemistry, 46, 3109-3115.

Gallagher, E., Gormley, T. R., \& Arendt, E. K. (2004). Recent advances in the formulation of gluten-free cereal based products. Trends in Food Science and Technology, 15, 143-152.

Glampedaki, P., Petzold, G., Dutschk, V., Miller, R., \& Warmoeskerken, M. C. G. (2012). Physicochemical properties of biopolymer-based polyelectrolyte complexes with controlled $\mathrm{pH} /$ thermo-responsiveness. Reactive and Functional Polymers, 72, 458-468.

Gujral, H. S., \& Rosell, C. M. (2004). Functionality of rice flour modified with a microbial transglutaminase. Journal of Cereal Science, 39, 225-230.

Gunaratne, A., \& Hoover, R. (2002). Effect of heat-moisture treatment on the structure and physicochemical properties of tuber and root starches. Carbohydrate Polymers, 49, 425-437.

Houben, A., Götz, H., Mitzscherling, M., \& Becker, T. (2010). Modification of the rheological behavior of amaranth (Amaranthus hypochondriacus) dough. Journal of Cereal Science, 51, 350-356.

ICC (2008). International Association for Cereal Chemistry. ICCStandard Methods No. 110/1.

ISO 7302 (1982). Cereals and cereal products-Determination of total fat content. Geneva, Switzerland

Lai, H. M. (2001). Effects of hydrothermal treatment on the physicochemical properties of pregelatinized rice flour. Food Chemistry, $72,455-463$.

Lai, P., Li, K. Y., Lu, S., \& Chen, H. H. (2011). Physicochemical characteristics of rice starch supplemented with dietary fibre. Food Chemistry, 127, 153-158.

Lan, W., Hihua, Y., Yun, Z., Bijun, X., \& Zhida, S. (2008). Morphological, physicochemical and textural properties of starch separated from Chinese water chestnut. Starch-Starke, 60, 181191.

Lawal, O. S., Lapasin, R., Bellich, B., Olayiwola, T. O., Cesàro, A., Yoshimura, M., et al. (2011). Rheology and functional properties of starches isolated from five improved rice varieties from West Africa. Food Hydrocolloids, 25, 1785-1792.

Lazaridou, A., Duta, D., Papageorgiou, M., Belc, N., \& Biliaderis, C. G. (2007). Effects of hydrocolloids on dough rheology and bread quality parameters in gluten-free formulations. Journal of Food Engineering, 79, 1033-1047.

Leach, H. W., McCowen, L. D., \& Schoch, T. J. (1959). Structure of the starch granule. I Swelling and solubility patterns of various starches. Cereal Chemistry, 36, 534-544.

Manohar, R. S., \& Rao, P. H. (2002). Interrelationship between rheological characteristic of dough and quality of biscuits; use of elastic recovery of dough to predict biscuit quality. Food Research International, 35, 807-813.

Marco, C., \& Rosell, C. M. (2008). Breadmaking performance of protein enriched, gluten-free breads. European Food Research and Technology, 227, 1205-1213. 
Mariotti, M., Lucisano, M., Pagani, M. A., \& Ng, P. K. W. (2009). The role of corn starch, amaranth flour, pea isolate, and Psyllium flour on the rheological properties and the ultrastructure of gluten-free doughs. Food Research International, 42, 963-975.

Miguelez, J. D. L. M., Bernárdez, M. M., \& Queijeiro, J. M. G. (2004). Composition of varieties of chestnuts from Galicia (Spain). Food Chemistry, 84, 401-404.

Miles, M. J., Morris, V. J., Orford, P. D., \& Ring, S. C. (1985). The role of amylose and amylopectin in the gelation and retrogradation of starch. Carbohydrate Research, 135, 271-281

Moreira, R., Chenlo, F., Torres, M. D., \& Prieto, D. M. (2010). Influence of the particle size on the rheological behaviour of chestnut flour doughs. Journal of Food Engineering, 100, 270-277.

Moreira, R., Chenlo, F., \& Torres, M. D. (2012a). Effect of shortenings on the rheology of gluten-free doughs: Study of chestnut flour with chia flour, olive and sunflower oils. Journal of Texture Studies, 43, 375-383.

Moreira, R., Chenlo, F., \& Torres, M. D. (2012b). Rheology of glutenfree doughs from blends of chestnut and rice flours. Food and Bioprocess Technology. doi:10.1007/s11947-012-0927-1.

Moroni, A. V., Bello, F. D., \& Arendt, E. K. (2009). Sourdough in gluten-free bread-making: an ancient technology to solve a novel issue. Food Microbiology, 26, 676-684.

Nunes, M. C., Raymundo, A., \& Sousa, I. (2004). Effect of thermal treatment and composition on the mechanical properties of pea/ kappa-carrageenan/starch desserts. In P. A. Williams \& G. O. Phillips (Eds.), Gums and Stabilisers for the Food Industry (Vol. 12, pp. 54-64). London, UK: Royal Society of Chemistry.

Nunes, M. C., Raymundo, A., \& Sousa, I. (2006). Rheological behaviour and microstructure of pea protein/k-carrageenan/ starch gels with different setting conditions. Food Hydrocolloids, 20, 106-113.

Onyango, C., Unbehend, G., \& Lindhuaer, M. G. (2009). Effect of cellulose-derivatives and emulsifiers on creep-recovery and crumb properties of gluten-free bread prepared from sorghum and gelatinized starch. Food Research International, 42, 949-955.

Piteira, M. F., Maia, J. M., Raymundo, A., \& Sousa, I. (2006). Extensional flow behaviour of natural fibre-filled dough and its relationship with structure and properties. Journal of nonNewtonian Fluid Mechanical, 137, 72-80.

Prosky, L. (2000). When is dietary fiber considered a functional food? Biofactors, 12, 289-297.

Rosalina, I., \& Bhattacharya, M. (2002). Dynamic rheological measurements and analysis of starch gels. Carbohydrate Polymers, 48, 191-202.

Rosell, C. M., \& Gómez, M. (2006). Rice. In Y. H. Hui (Ed.), Bakery Products: Science and Technology (pp. 123-133). Iowa, USA: Blackwell Publishing.

Rosell, C. M., \& Marco, C. (2008). Rice. In E. K. Arendt \& F. Dal Bello (Eds.), Gluten Free Cereal Product and Beverages. London, UK: Academic Press.

Sacchetti, G., Pinnavaia, G. G., Guidolin, E., \& Dalla Rosa, M. (2004). Effects of extrusion temperature and feed composition on the functional, physical and sensory properties of chestnut and rice flour based snack like products. Food Research International, 37, 527-534.

Santos, E., Rosell, C. M., \& Collar, C. (2008). Retrogradation kinetics of high fibre wheat flour blends: A calorimetric approach. Cereal Chemistry, 85, 450-458.

Sodhi, N. S., Sasaki, T., Lu, Z.-H., \& Kohyama, K. (2010). Phenomenological viscoelasticity of some rice starch gels. Food Hydrocolloids, 24, 512-517.

Song, J. Y., \& Shin, M. (2007). Effects of soaking and particle sizes on the properties of rice flour and gluten-free rice bread. Food Science and Biotechnology, 16, 759-764.

Takahashi, T., Miura, M., Ohisa, N., Mori, K., \& Kobayashi, S. (2005). Heat treatments of milled rice and properties of the flours. Cereal Chemistry, 82, 228-232.

Vasconcelos, M. C. B. M., Nunes, F., García-Viguera, C., Benett, R. N., Rosa, E. A. S., \& Ferreira-Cardoso, J. V. (2010). Industrial processing effects on chestnut fruits (Castanea sativa Mill.). 3. Minerals, free sugars, carotenoids and antioxidant vitamins in chestnut fruits (Castanea sativa Mill.). International Journal of Food Science and Technology, 45, 496-505.

$\mathrm{Xu}$, D., Wang, X., Jiang, J., Yuan, F., \& Gao, Y. (2012). Impact of whey protein - Beet pectin conjugation on the physicochemical stability of beta-carotene emulsions. Food Hydrocolloids, 28, $258-266$. 